\title{
Myeloperoxidase (MPO) and high sensitivity C-reactive protein (hsCRP) as inflammatory biomarkers of endothelial and leukocyte activation in overweight hypertensive patients
}

\author{
Dunja Buljubasic ${ }^{1}$, Ines Drenjancevic ${ }^{2}$, Aleksandar Kibel ${ }^{2,3}$, Lada Zibar ${ }^{4,5}$, Vedrana Vizjak ${ }^{6}$, \\ Sanja Mandic ${ }^{7,8}$, Tatjana Bacun, ${ }^{90}$ \\ ${ }^{1}$ Department of Nephrology and Dialysis, Internal Medicine Clinic, Osijek University Hospital Centre, Osijek, Croatia \\ ${ }^{2}$ Department of Physiology and Immunology, Faculty of Medicine, University Josip Juraj Strossmayer in Osijek, Osijek, Croatia \\ ${ }^{3}$ Department of Heart and Vascular Diseases, Internal Medicine Clinic, Osijek University Hospital Centre, Osijek, Croatia \\ ${ }^{4}$ Department of Nephrology, Clinical Hospital Merkur, Zagreb, Croatia \\ ${ }^{5}$ Department of Pathophysiology, Faculty of Medicine, University Josip Juraj Strossmayer, Osijek, Croatia \\ ${ }^{6}$ Department of Medicine Zulekha Hospital Sharjah, United Arab Emirates \\ ${ }^{7}$ Department for Chemistry, Biochemistry and Clinical Chemistry, Faculty of Medicine, University Josip Juraj Strossmayer, Osijek, Croatia \\ ${ }^{8}$ Department of Clinical Laboratory Diagnostics, Osijek University Hospital Centre, Osijek, Croatia \\ ${ }^{9}$ Department of Internal Medicine, Faculty of Medicine, University Josip Juraj Strossmayer Osijek, Croatia \\ ${ }^{10}$ Department of Endocrinology and Metabolic Disease, Internal Medicine Clinic, Osijek University Hospital Centre, Osijek, Croatia
}

\begin{abstract}
Background: Low-grade inflammation mediates the relation between overweight and the development of cardiovascular diseases. The study aimed to examine if myeloperoxidase (MPO) and hsCRP (high-sensitivity C-reactive protein) in overweight hypertensive patients can be used as biomarkers of endothelial and leukocyte activation.

Material and methods: Seventy-five subjects were included in the study; 38 had essential arterial hypertension $(\mathrm{AH})$ and 37 were normotensive controls $(\mathrm{NC})$, subsequently divided into overweight (OW; BMI $\geq 25 \mathrm{~kg} / \mathrm{m}^{2}$ ) and normal weight subgroups (NW; BMI $<25 \mathrm{~kg} / \mathrm{m}^{2}$ ). Body mass index (BMI), inflammatory markers concentrations, association of MPO and hsCRP with AH and/or overweight were assessed.

Results: AH patients had higher MPO (median 132.5 pmol/L, IQR: 53.8-691.9) $(\mathrm{p}<0.001)$, while hsCRP did not significantly differ compared to normotensive controls $(\mathrm{NC})$. NW-AH patients had higher MPO ( $\mathrm{p}=0.02)$ than normotensive NW patients. MPO was similar between normotensive patients OW and NW, while hsCRP concentration was significantly higher in the OW (median $1.85 \mathrm{mg} / \mathrm{L}$, IQR: 0.47-7.19) ( $\mathrm{p}=0.01)$ compared to NW. OW-AH patients had significantly higher MPO (median 137.4 pmol/L, IQR: 53.80-703.4) ( $p=0.002)$ compared to normotensive NW and OW $(\mathrm{p}<0.001)$ patients, likely reflecting neutrophilic activation in hypertension. Additionaly, OW-AH patients had significantly higher hsCRP (median $1.71 \mathrm{mg} / \mathrm{L}, \mathrm{IQR}: 0.22-14)(\mathrm{p}=0.005)$ than normotensive NW patients. hsCRP significantly positively correlated with BMI in both $\mathrm{AH}(\rho=0.41, \mathrm{p}=0,009)$ and $\mathrm{NC}$ groups $(\rho=0.38, \mathrm{p}=0.01)$, while MPO did not correlate, supporting inflammation in OW, particularly in OW with AH.
\end{abstract}

Address for correspondence: Tatjana Bacun, Department of Internal Medicine, Faculty of Medicine, University Josip Juraj Strossmayer Osijek, Croatia; e-mail: tbacun@gmail.com

This article is available in open access under Creative Common Attribution-Non-Commercial-No Derivatives 4.0 International (CC BY-NC-ND 4.0) license, allowing to download articles and share them with others as long as they credit the authors and the publisher, but without permission to change them in any way or use them commercially

VM Copyright (C) 2021 Via Medica, ISSN 2449-6170, e-ISSN 2449-6162 
Conclusions: All together, the results suggest that inflammation may mediate mutual association of $\mathrm{AH}$ and $\mathrm{OW}$, suggesting MPO as inflammatory biomarker for $\mathrm{AH}$ and hsCRP for overweight.

Key words: arterial hypertension; overweight; myeloperoxidase; high sensitivity C-reactive protein; inflammation; biomarker

\section{Introduction}

Arterial hypertension $(\mathrm{AH})$ is a major independent risk factor for development of cardiovascular (CV) diseases, such as heart failure and myocardial infarction, as well as the primary cause of stroke which makes it a significant public health problem [1]. Another CV risk factor and a global health epidemic is overweight $(\mathrm{OW})$, a chronic disease with distinct metabolic and endocrine disorders, which result in a number of severe chronic complications [2]. The common denominator of the both, $\mathrm{AH}[3,4]$ and overweight, is inflammation, which causes endothelial dysfunction $[5,6]$ and has a key role in the development and progression of atherosclerosis [7].

C-reactive protein (CRP) is an inflammatory biomarker synthesized in hepatocytes in response to primary stimulation by interleukin 6 (IL-6) [8]. A recent study demonstrated that high sensitive CRP (hsCRP) (which is a term for a more sensitive assay of CRP) is involved in mechanisms that lead to development of $\mathrm{AH}$ [9]. hsCRP can be considered as biomarker of the process of endothelial dysfunction and, at supraphysiological concentrations, as a predictor of vascular disease [10].

Several studies have shown that CRP impaired endothelial vasoreactivity in vivo $[11,12]$ by inhibiting endothelial nitric oxide synthase (eNOS) activity in vitro and in vivo, reducing $\mathrm{NO}$ availability, and by predisposing blood vessels to chronic vasospasm, leading to an increase in total vascular resistance and $\mathrm{AH}$ [13]. Interestingly, there are evidences that hsCRP may be also secreted by other cells than hepatocytes, such as smooth muscle cells and adipocytes [14]. In addition, prolonged periods of low-grade systemic inflammation may explain the higher risk for high blood pressure observed among overweight people [15].

Myeloperoxidase (MPO) is a lysosomal enzyme present in neutrophils and monocytes, released during their activation to the surface of vascular endothelial cells and around them, following leukocyte degranulation [16]. MPO has affinity to both, the endothelial and the leukocyte's surface and may con- tribute to leukocytes attraction and recruitment to endothelial cells by its electrostatic effect of positively surface charge, which is a catalysis-independent function of the enzyme [17].

MPO catalyzes the production of hypochloric acid and a range of other highly reactive species. These MPO-derived reactive substances may damage the arterial wall, thereby reducing its elasticity [18]. Another potentially important consequence of MPO activity is consumption of $\mathrm{NO}$ and induction of endothelial dysfunction [19].

MPO is rapidly taken up by endothelial cells by a transcytotic process and accumulates within the subendothelial space, positioning it anatomically to interfere with the effects of NO in the vessel wall [20]. Together, these mechanisms may lead to endothelial dysfunction and subsequently increased blood pressure. And while some reports of studies in human subjects have shown a significant association between blood pressure and hs-CRP elevation in people with hypertension [21, 22] other studies showed no significant relation between hypertension and hs-CRP $[23,24]$.

The aim of the study was to examine if myeloperoxidase (MPO) and hsCRP in overweight hypertensive patients can be used as biomarkers of endothelial and leukocyte activation and their interaction.

\section{Material and methods}

The study included 75 examinees, 43 men and 32 women, ranging in age from 20 to 70 years (median 42). Thirty-eight patients were recently diagnosed having essential $\mathrm{AH}$ that lasted less than a year $\mathrm{AH}$ stage 1 according to the European Hypertension Guidelines 2013 - systolic blood pressure $\geq 140 \mathrm{~mm}$ $\mathrm{Hg}$ and/or diastolic blood pressure $\geq 90 \mathrm{~mm} \mathrm{Hg}$ ), while 37 were normotensive controls. The study was designed as a cross-sectional investigation. The examinees were recruited from the ambulatory office for nephrology and hypertension, in the Department of Nephrology, Osijek University Hospital, in Osijek, Croatia (Fig. 1). 


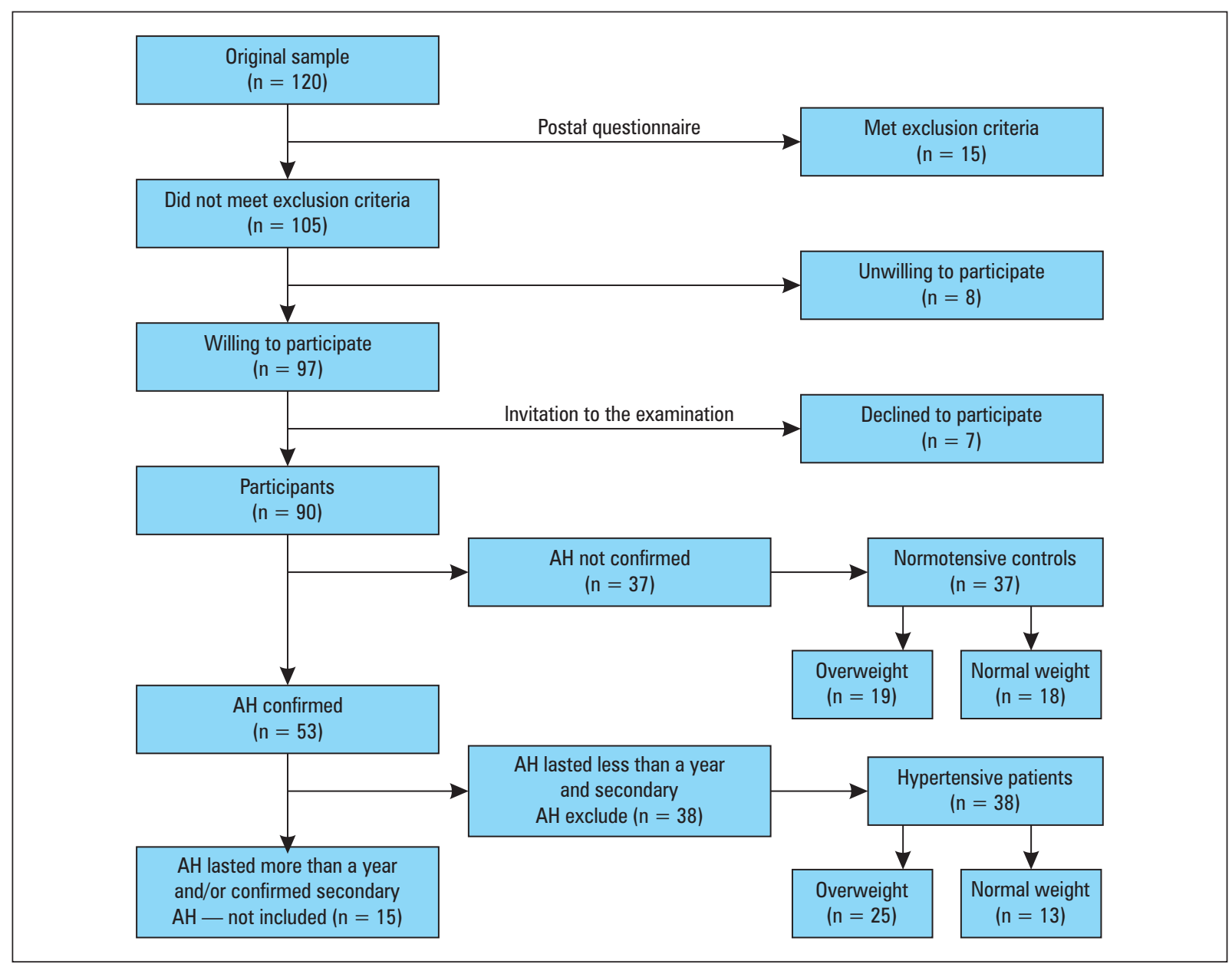

Figure 1. Formation of the sample in the study

Exclusion criteria were diabetes, liver disease, renal disease and/or serum creatinine above $97 \mu \mathrm{mol} / \mathrm{L}$ for men and $80 \mu \mathrm{mol} / \mathrm{L}$ for women, myocardial infarction, stroke and use of nonsteroidal anti-inflammatory drugs or glucocorticoids.

The groups were further subdivided according to the body mass index (BMI) into an overweight (OW) group, with BMI $\geq 25 \mathrm{~kg} / \mathrm{m}^{2}$, and a normal weight (NW) group, with BMI $<25 \mathrm{~kg} / \mathrm{m}^{2}$. The studied groups' characteristics are shown in the Table 1.

The previous workup for diagnosis of essential $\mathrm{AH}$ was as following: all patients were examined for medical history, then underwent physical examination that included arterial blood pressure measurement using calibrated mercury sphygmomanometer with the suitable dimension cuff; blood pressure (BP) readings were taken while patients were in the sitting position and rested for 5 minutes; their BP was taken three times consecutively and the mean value was calculated for systolic and diastolic BP, respectively. The same procedure was performed in the controls group to exclude AH. During the study, the hypertensive patients did not receive anti-hypertensive therapy for 2 weeks before the blood sampling. In patients with $\mathrm{AH}$ additional laboratory tests were done to exclude secondary $\mathrm{AH}$ : plasma renin activity, aldosterone, metanephrine and normetanephrine in the 24-hour urine, ACTH, circadian rhythm cortisol, duplex sonography of the kidneys, endogenous creatinine clearance and 24-hour proteinuria to assess renal function. $\mathrm{Pa}$ tients' height and weight measurements were taken in the morning and the following laboratory tests were performed: total cholesterol, high density lipoprotein (HDL), low density lipoprotein (LDL), triglycerides, plasma glucose, urea, creatinine, urate and urinalysis. All examinees were informed about the research methods, ethical principles and the purpose of the research prior to its beginning and they all gave their written informed consent.

MPO and hsCRP concentration measurements Concentrations of MPO and hsCRP were determined by aArchitect 1000i (ABBOT, United 
Table 1. Demographic and laboratory characteristics of arterial hypertension (AH) patients and normotensive controls (NC) ( $\mathrm{n}=75)$

\begin{tabular}{|c|c|c|c|c|}
\hline & \multicolumn{2}{|c|}{ Group } & \multirow{2}{*}{ Test value } & \multirow{2}{*}{$\mathbf{p}$} \\
\hline & $A H(n=38)$ & $N C(n=37)$ & & \\
\hline Age [yrs] & $42 \pm 14(20-70)$ & $40 \pm 9(24-55)$ & $t=0.704$ & 0.48 \\
\hline Sex (men/women) (n) & $21 / 17$ & $22 / 15$ & $\chi^{2}=0.13$ & 0.71 \\
\hline Cholesterol [mmol/L] & $5.44 \pm 1.05$ & $5.55 \pm 1.81$ & $t=-0.33$ & 0.74 \\
\hline $\mathrm{HDL}[\mathrm{mmol} / \mathrm{L}]$ & $1.31 \pm 0.34$ & $1.4 \pm 0.34$ & $t=-0.86$ & 0.39 \\
\hline LDL [mmol/L] & $3.38 \pm 1.03$ & $3.35 \pm 1.44$ & $t=0.10$ & 0.92 \\
\hline Triglycerides [mmol/L] & $1.38(0.37-5.65)$ & $1.62(0.34-9.94)$ & $z=-0.81$ & $0.42^{\mathrm{a}}$ \\
\hline BMI $\left[\mathrm{kg} / \mathrm{m}^{2}\right]$ & $27.97(19.33-45.61)$ & $25.2(19.49-34.29)$ & $z=-3.38$ & $0.001^{\mathrm{a}}$ \\
\hline hsCRP [mg/L] & $1.62(0.22-14)$ & $1.05(0.13-7.19)$ & $z=-1.63$ & $0.09^{\mathrm{a}}$ \\
\hline MPO [pmol/L] & $132.5(53.8-691.9)$ & $73(28.6-859.3)$ & $z=-4.60$ & $<0.001^{\mathrm{a}}$ \\
\hline
\end{tabular}

HDL — high density lipoproteins; LDL — low density lipoproteins; BMI — body mass index; hsCRP — high-sensitivity C-reactive protein; MPO — myeloperoxidase; ${ }^{a}$ Mann-Whitney test

States) analyzer in EDTA plasma, applying chemiluminescence microparticle immunoassay (CMIA). Serum hsCRP was determined using immunoturbidimetry test for quantitative determination on Olympus AU-680 analyzer (Beckman Coulter, Switzerland).

\section{Statistical analyses}

The data were statistically analyzed by SPSS 15.0 for Windows (SPSS Inc., Chicago, IL, USA). Categorical variables were expressed as proportions and percentages. Normality of distribution of numerical data was analyzed by Kolmogorov-Smirnov test. Differences in categorical variables were examined by chi-square test. Differences in numerical variables were tested by Student's t-test for normally distributed variables and by Mann-Whitney test for nonparametric statistics. Binary logistic regression (Hosmer-Leveshow goodness of fit test) was used for multivariate analysis. Spearman's $\rho$ was determined for correlations between numeric variables. Values of $\mathrm{p}<0.05$ were considered statistically significant.

\section{Results}

\section{Myeloperoxidase and hsCRP concentrations}

Table 1 shows the general demographic characteristics of the groups. The patients with $\mathrm{AH}$ were not different from normotensive individuals in age, gender, plasma concentration of cholesterol and triglycerides. AH patients had higher BMI $(\mathrm{p}=0.001)$ and higher MPO concentrations (median 132.5 $\mathrm{pmol} / \mathrm{L}, 53.8-691.9)$ compared to the normotensive group (NC) (median $73 \mathrm{pmol} / \mathrm{L}, 28.60-859.3$ ) $(\mathrm{p}<0.001)$. No difference in hsCRP concentrations were found between the two groups $(\mathrm{p}=0.09)$.

Overweight hypertensive (OW-AH) and overweight normotensive (OW-NC) examinees together had higher hsCRP (median $1.8 \mathrm{mg} / \mathrm{L}, 0.22-14$ ) $(\mathrm{p}=0.01)$ compared to normal weight hypertensive (NW-AH) and normal weight normotensive (NWNC) examinees taken together (Tab. 2). MPO did not differ between all OW and all NW examinees.

MPO concentration and hsCRP concentration were not different in hypertensive OW patients compared to NW-AH patients (MPO p $=0.87$ and

Table 2. Differences in high-sensitivity C-reactive protein (hSCRP) and myeloperoxidase (MPO) within the entire and within the hypertensive group according to body mass index (BMI)

\begin{tabular}{|c|c|c|c|c|}
\hline \multirow[b]{2}{*}{ Entire group $(n=75)$} & \multicolumn{2}{|c|}{ BMI $\left[\mathrm{kg} / \mathrm{m}^{2}\right]$} & \multirow[t]{2}{*}{$z$} & \multirow[t]{2}{*}{$\mathbf{p}$} \\
\hline & $\geq 25(n=48)$ & $<25(n=27)$ & & \\
\hline hsCRP [mg/L] & $1.80(0.22-14.00)$ & $1.04(0.13-5.50)$ & -2.42 & $0.02^{\mathrm{a}}$ \\
\hline MPO [pmol/L] & $100.55(28.6-703.40)$ & $98.90(30.8-859.3)$ & -0.57 & 0.57 \\
\hline Hypertensive group ( $\mathrm{n}=38$ ) & $\geq 25(n=25)$ & $<25(n=13)$ & & \\
\hline hsCRP [mg/L] & $1.71(0.22-14.00)$ & $1.55(0.29-5.50)$ & -0.49 & 0.62 \\
\hline MPO [pmol/L] & $137.4(53.80-703.4)$ & $132.50(37.75-691.90)$ & 0.16 & 0.87 \\
\hline
\end{tabular}

${ }^{a}$ Mann-Whitney test 
Table 3. Differences in myeloperoxidase (MPO) and high sensitivity C-reactive protein (hsCRP) between arterial hypertension (AH) patients and normotensive controls (NC) divided according to body mass index (BMI)

\begin{tabular}{|c|c|c|c|c|}
\hline BMI $\left[\mathrm{kg} / \mathrm{m}^{2}\right]$ & \multicolumn{2}{|c|}{ MPO [pmol/L] } & $\mathbf{z}$ & $\mathbf{p}$ \\
\hline & $\mathrm{AH}(\mathrm{n}=38)$ & $N C(n=37)$ & & \\
\hline$<25$ & $132.5(37.75-691.9)^{*} \dagger$ & $78.5(30.8-59.3)^{*} \ddagger$ & $*-2.21$ & $0.03^{\mathrm{a}}$ \\
\hline \multirow[t]{3}{*}{$\geq 25$} & $137.4(53.8-703.4) \ddagger \S$ & $73(28.6-131.5) \dagger \S$ & $\S-4.04$ & $<0.001^{a}$ \\
\hline & \multicolumn{2}{|c|}{ hsCRP [mg/L] } & & \\
\hline & $\mathrm{AH}(\mathrm{n}=38)$ & $N C(n=37)$ & & \\
\hline$<25$ & $1.55(0.29-5.5)^{*} \dagger$ & $0.89(0.13-4.64)^{*} \ddagger$ & ${ }^{*}-1.42$ & 0.15 \\
\hline$\geq 25$ & $1.71(0.22-14) \ddagger \S$ & $1.85(0.47-7.19) \dagger \S$ & $\S-0.34$ & 0.73 \\
\hline
\end{tabular}

${ }^{a}$ Mann Whitney test; MPO: $t z=-0.64, p=0.008 ; \ddagger z=-3.15, p=0.002 ;$ hsCRP: $t z=-0.566, p=0.572, \ddagger z=2.778, p=0.005$

hsCRP p $=0.61$, respectively) (Tab. 2). OW normotensive subjects did not significantly differ from NW normotensive subjects in MPO concentrations (median $73 \mathrm{pmol} / \mathrm{L}, 28.60-131.50$ in OW compared to median $78.05 \mathrm{pmol} / \mathrm{L}, 30.80-859.30$ in NW) $(\mathrm{p}=0.56)$, while significantly higher concentrations of hsCRP were found in overweight normotensive subjects (OW-NC) (median 1.85 mg/L, 0.47-7.19 compared to median $0.89 \mathrm{mg} / \mathrm{L}, 0.13-4.64$ in NW) $(\mathrm{p}=0.01)$.

OW-AH patients had significantly higher MPO (median $137.4 \mathrm{pmol} / \mathrm{L}, 53.8-703.4)(\mathrm{p}=0.002)$ and hsCRP (median $1.71 \mathrm{mg} / \mathrm{L}, 0.22-14)(\mathrm{p}=0.005)$ compared to NW-NC patients. OW-AH patients had significantly higher MPO compared to normotensive OW subjects $(\mathrm{p}<0.001)$, while hsCRP did not differ between those two OW subgroups $(\mathrm{p}=$ 0.72) (Tab. 3).

\section{Multivariate analysis}

Multivariate analysis (binary logistic regression) with overweight, hsCRP and MPO as covariates showed that overweight was independently significantly predictive for $\mathrm{AH}$, unlike hsCRP, while higher MPO increased risk for $\mathrm{AH}$ with statistically marginal significance (Tab. 4).

\section{Correlations between MPO and hsCRP}

Within the entire examined group $(\mathrm{n}=75)$ Spearman Rank Correlation Analysis of body mass index (BMI, $\mathrm{kg} / \mathrm{m}^{2}$ ) with serum concentrations of hsCRP and with MPO showed that hsCRP and MPO posi- tively correlated with BMI (for hsCRP correlation coefficient $(\rho)=0.44, \mathrm{p}<0.001$; for MPO $\rho=0.24$, $\mathrm{p}=0.038)$.

hsCRP significantly positively correlated with BMI in hypertensive $(\mathrm{n}=38, \rho=0.42, \mathrm{p}=0.01)$ and in normotensive $(\mathrm{n}=37, \rho=0.39, \mathrm{p}=0.01)$ groups respectively, while MPO did not correlate with BMI in any of these two groups (in the hypertensive group $\rho=0.18, \mathrm{p}=0.26$, whereas in the normotensive group $\rho=-0.12, \mathrm{p}=0.48)$.

\section{Discussion}

The main findings of our study include: a) significant elevation of MPO concentration in hypertensive patients, irrespective of their BMI; b) significantly increased hsCRP in overweight subjects, irrespective of $\mathrm{AH}$; and c) hsCRP significantly positively correlates with BMI in all participants, irrespective of $\mathrm{AH}$. Nevertheless, MPO and hsCRP were significantly increased at the same time only in patients who were both hypertensive and overweight compared to the normotensive overweight and normal weight subjects. Our results are in concordance with the data obtained in study by Heine et al. [25] in which the concentrations of MPO in the circulation positively associated with systolic and diastolic blood pressure, and in concordance with the data obtained in study by Yudkin et al. [26] which showed relationships between levels of CRP and measures of overweight in healthy subjects without hypertension.

Table 4. Binary logistic regression (Hosmer-Lemeshow goodness of fit test) for arterial hypertension $(n=38)$ as dependent variable $(n=75)$

\begin{tabular}{|l|c|c|c|}
\hline Covariate & $\mathbf{p}$ & $\mathbf{E x p}(\mathbf{B})$ & $\mathbf{9 5 \%}$ CI \\
\hline Obesity & 0.044 & 3.00 & $1.03-8.75$ \\
\hline hsCRP $[\mathrm{mg} / \mathrm{L}]$ & 0.247 & 1.19 & $0.88-1.61$ \\
\hline MPO $[\mathrm{pmol} / \mathrm{L}]$ & 0.069 & 1.00 & $1-1.01$ \\
\hline
\end{tabular}

hsCRP — high-sensitivity C-reactive protein; MPO — myeloperoxidase; $\mathrm{Cl}$ — confidence interval 
Our results suggest that hypertensive patients might have higher neutrophil activation than normotensive subjects, reflected by MPO increase, and also suggest potential role of inflammation in the development of $\mathrm{AH}$, by MPO affecting the local vascular level of oxidative stress, thus possibly altering the synthesis and degradation of vasodilating and vasoconstricting factors, as discussed in [27].

Previous studies confirmed that inflammatory process is an integral part of $\mathrm{AH}$ by showing elevated concentration of CRP in hypertensive patients [28]. Moreover, it has been suggested that elevated CRP in healthy humans lead to an increased risk of developing $\mathrm{AH}$ [29]. CRP in arterial wall promotes expression of adhesion molecules E-selectin, cell adhesion molecules wall 1 (VCAM-1) and intercellular adhesion molecule1 (ICAM-1) on endothelial cells. Dysfunction of endothelial cells, as induced by CRP, renders reduced $\mathrm{NO}$ synthesis, resulting in enhanced reactivity of blood vessel wall [30].

Overweight per se is a condition of chronic inflammation which could contribute to a further endothelial damage, worsening the vascular disease and promoting development or maintenance of $\mathrm{AH}$ [31]. Thus, one of the goals of the present study was to evaluate the potential mutual interaction of overweight and hypertension.

Plasma concentration of hsCRP has been shown to be strongly associated with OW and OW-related diseases, including diabetes mellitus, and hyperlipidemia [31]. In the present study, overweight hypertensive and normotensive patients together had significantly increased hsCRP, which is in accordance with the literature $[31,32]$. Moreover, there was a significant positive correlation between the concentrations of hsCRP and BMI within the entire examined group. All together, these findings support hypothesis that hsCRP is a good marker of overweight-associated inflammation, independently of the blood pressure.

Although there was a positive correlation between hsCRP and BMI in the group of hypertensive patients, there was no difference in hsCRP levels between OW and NW-AH patients. In support of this, the results of The Relationship between Blood Pressure and C-Reactive Protein in the Multi-Ethnic Study of Atherosclerosis (MESA) study [33] demonstrated that some hypertensive groups showed a greater association, while some groups showed no difference in CRP in respect with the hypertension status. MESA showed that Chinese participants had the lowest CRP concentration but the largest difference in CRP by hypertension status, followed by Caucasians and African Americans, whereas Hispan- ics had no significant difference in CRP by hypertension status. It might be that some other factors, besides being OW, affect the value of CRP in $\mathrm{AH}$. Nevertheless, the level of systemic inflammatory markers such as CRP, white blood cell count and albumin are at least partially determined by genetic factors [34].

Adipose tissue has been characterized as a dynamic endocrine organ that produces proinflammatory cytokines. Overweight is a well-known predictor of $\mathrm{AH}$ and may confound the association between inflammation and hypertension [35]. However, the finding that hsCRP statistically significantly positively correlated with BMI in normotensive patients might support a previously published research which found that the protein may be released by adipocytes. Our data also showed a positive correlation between hsCRP and BMI in normotensive group. Therefore, it can be concluded that overweight, as a chronic persistent process, affects CRP levels, thus increasing the risk of developing $\mathrm{CV}$ disease in normotensive participants, i.e. independently of $\mathrm{AH}$. In support of this thesis is large prospective epidemiological study that have shown that plasma level of hsCRP was a strong independent risk for a future myocardial infarction, stroke, peripheral arterial disease and vascular death among individuals without known previous CV disease [36].

While concentration of MPO activity was found significantly elevated in hypertensive patients in comparison with the normotensive, regardless of BMI, high-sensitivity C-reactive protein between those groups were different only in respect to BMI. That means that only OW-AH patients had significantly higher hsCRP compared to the NWnormotensive subjects, while hsCRP did not differ between OW-AH patients and OW-normotensive subject, suggesting that the association between hsCRP and OB could be stronger in hypertensive individuals, which makes it more difficult to distinguish independent effects of inflammation or overweight on $\mathrm{AH}$.

Our results showed a positive correlation between $\mathrm{BMI}$ and hsCRP in hypertensive and normotensive patients, but with no impact on MPO, suggesting that the increase in body weight induces endothelial inflammation processes, which may contribute to the development of hypertension.

Taken together, the results of our study lead to the conclusion that the effect of hsCRP and MPO in the development of $\mathrm{AH}$ might be strengthened by the increase in body weight, due to the observed fact that only patients who are hypertensive and overweight at the same time had significantly increased both hsCRP and MPO compared to all normotensive 
subjects, regardless of their BMI. Additionally, the findings could reflect that overweight might participate in the development of AH due to the proinflammatory processes.

\section{Conclusion}

In the present study, MPO was significantly higher in patients with $\mathrm{AH}$, irrespectively of BMI, which indicates neutrophilic activation concomitant to hypertension. OW is associated with proinflammatory effects, as evident by increase in hsCRP in OW participants (both hypertensive and normotensive), but without effect on leukocyte activations in any of the studied groups. Only in patients with both hypertension and overweight, there were significantly higher concentrations of MPO and hsCRP compared to the healthy normal weight subjects who had either $\mathrm{AH}$ or OW solely. Taken together, our data provide evidence that inflammation may be an important link between overweight and $\mathrm{AH}$ and that $\mathrm{MPO}$ and hsCRP may serve as good markers for inflammatory processes common to these two diseases. Altogether, results suggest that inflammation may mediate mutual association of $\mathrm{AH}$ and $\mathrm{OW}$, suggesting $\mathrm{MPO}$ as an inflammatory marker for $\mathrm{AH}$ and hsCRP for overweight.

\section{Ethical Standards}

The study protocol and procedures conformed to the standards set by the latest revision of the Declaration of Helsinki. The study was approved by the institutional Ethical Committee and by Ethical Committee of the Faculty of Medicine Osijek, University Josip Juraj Strossmayer Osijek, Croatia.

\section{Informed consent}

Informed consent was obtained from all patients for being included in the study.

\section{References}

1. Lewington S, Clarke R, Qizilbash N, et al. Prospective Studies Collaboration. Age-specific relevance of usual blood pressure to vascular mortality: a meta-analysis of individual data for one million adults in 61 prospective studies. Lancet. 2002; 360(9349): 1903-1913, doi: 10.1016/s0140-6736(02)11911-8, indexed in Pubmed: 12493255.

2. Jelaković B, Željković-Vrkić T, Pećin I, et al. Arterijska hipertenzija u Hrvatskoj.Rezultati EH-UH studije. Acta Med Croatica. 2007; 61: 287-92.

3. Boos CJ, Lip GYH. Is hypertension an inflammatory process? Curr Pharm Des. 2006; 12(13): 1623-1635, doi: 10.2174/138 161206776843313 , indexed in Pubmed: 16729874.

4. Kakar P, Lip GYH. Towards understanding the aetiology and pathophysiology of human hypertension: where are we now?
J Hum Hypertens. 2006; 20(11): 833-836, doi: 10.1038/ sj.jhh.1002082, indexed in Pubmed: 16929340.

5. Sinisalo J, Paronen J, Mattila KJ, et al. Relation of inflammation to vascular function in patients with coronary heart disease. Atherosclerosis. 2000; 149(2): 403-411, doi: 10.1016/s00219150(99)00333-0, indexed in Pubmed: 10729391.

6. Schwedler SB, Kuhlencordt PJ, Ponnuswamy PP, et al. Native C-reactive protein induces endothelial dysfunction in ApoE/- mice: implications for iNOS and reactive oxygen species. Atherosclerosis. 2007; 195(2): e76-e84, doi: 10.1016/j.atherosclerosis.2007.06.013, indexed in Pubmed: 17669410.

7. Libby P. Inflammation in atherosclerosis. Nature. 2002; 420(6917): 868-874, doi: 10.1038/nature01323, indexed in Pubmed: 12490960

8. Steffel J, Lüscher TF. Predicting the development of atherosclerosis. Circulation. 2009; 119(7): 919-921, doi: 10.1161/CIRCULATIONAHA.108.846725, indexed in Pubmed: 19237671.

9. Kim JS, Kang TS, Kim JB, et al. Significant association of Creactive protein with arterial stiffness in treated non-diabetic hypertensive patients. Atherosclerosis. 2007; 192(2): 401-406, doi: $10.1016 /$ j.atherosclerosis.2006.05.025, indexed in Pubmed: 16782104.

10. Souza JR, Oliveira RT, Blotta MH, et al. Serum levels of interleukin-6 (Il-6), interleukin-18 (Il-18) and C-reactive protein (CRP) in patients with type-2 diabetes and acute coronary syndrome without ST-segment elevation. Arq Bras Cardiol. 2008; 90(2): 86-90, doi: 10.1590/s0066-782×2008000200004, indexed in Pubmed: 18392379.

11. Venugopal SK, Devaraj S, Yuhanna I, et al. Demonstration that C-reactive protein decreases eNOS expression and bioactivity in human aortic endothelial cells. Circulation. 2002; 106(12): 1439-1441, doi: 10.1161/01.cir.0000033116.22237.f9, indexed in Pubmed: 12234944.

12. Hein TW, Singh U, Vasquez-Vivar J, et al. Human C-reactive protein induces endothelial dysfunction and uncoupling of eNOS in vivo. Atherosclerosis. 2009; 206(1): 61-68, doi: 10.1016/j. atherosclerosis.2009.02.002, indexed in Pubmed: 19268941.

13. Guan H, Wang P, Hui R, et al. Adeno-associated virus-mediated human C-reactive protein gene delivery causes endothelial dysfunction and hypertension in rats. Clin Chem. 2009; 55(2): 274-284, doi: $10.1373 /$ clinchem.2008.115857, indexed in Pubmed: 19056836.

14. Calabro P, Chang DW, Willerson JT, et al. Release of C-reactive protein in response to inflammatory cytokines by human adipocytes: linking obesity to vascular inflammation. J Am Coll Cardiol. 2005; 46(6): 1112-1113, doi: 10.1016/j.jacc.2005.06.017, indexed in Pubmed: 16168299.

15. Mendall MA, Patel P, Ballam L, et al. C reactive protein and its relation to cardiovascular risk factors: a population based cross sectional study. BMJ. 1996; 312(7038): 1061-1065, doi: 10.1136/ bmj.312.7038.1061, indexed in Pubmed: 8616412.

16. Norman PE, Powell JT. Vitamin D, shedding light on the development of disease in peripheral arteries. Arterioscler Thromb Vasc Biol. 2005; 25(1): 39-46, doi: 10.1161/01. ATV.0000148450.56697.4a, indexed in Pubmed: 15499037.

17. Klinke A, Nussbaum C, Kubala L, et al. Myeloperoxidase attracts neutrophils by physical forces. Blood. 2011; 117(4): 1350-1358, doi: 10.1182/blood-2010-05-284513, indexed in Pubmed: 20980678.

18. Schindhelm RK, van der Zwan LP, Teerlink T, et al. Myeloperoxidase: a useful biomarker for cardiovascular disease risk stratification? Clin Chem. 2009; 55(8): 1462-1470, doi: 10.1373/ clinchem.2009.126029, indexed in Pubmed: 19556446.

19. Abu-Soud HM, Hazen SL. Nitric oxide is a physiological substrate for mammalian peroxidases. J Biol Chem. 2000; 275(48): 37524-37532, doi: $10.1074 /$ jbc.275.48.37524, indexed in Pubmed: 11090610

20. Eiserich JP, Baldus S, Brennan ML, et al. Myeloperoxidase, a leukocyte-derived vascular NO oxidase. Science. 2002; 296(5577): 2391-2394, doi: 10.1126/science.1106830, indexed in Pubmed: 12089442. 
21. Sung KC. High sensitivity C-reactive protein as an independent risk factor for essential hypertension. Am J Hypertens. 2003; 16(6): 429-433, doi: 10.1016/s0895-7061(03)00566-1, indexed in Pubmed: 2799089.

22. Bautista LE, López-Jaramillo P, Vera LM, et al. Is C-reactive protein an independent risk factor for essential hypertension? J Hypertens. 2001; 19(5): 857-861, doi: 10.1097/00004872200105000-00004, indexed in Pubmed: 11393667.

23. Shafi Dar M, Pandith AA, Sameer AS, et al. hs-CRP: A potential marker for hypertension in Kashmiri population. Indian J Clin Biochem. 2010; 25(2): 208-212, doi: 10.1007/s12291-0100037-7, indexed in Pubmed: 23105911.

24. Bautista LE, Vera LM, Arenas IA, et al. Independent association between inflammatory markers (C-reactive protein, interleukin-6, and TNF-alpha) and essential hypertension. J Hum Hypertens. 2005; 19(2): 149-154, doi: 10.1038/sj.jhh.1001785, indexed in Pubmed: 15361891.

25. Van der Zwan LP, Scheffer PG, Dekker JM, et al. Hyperglycemia and oxidative stress strengthen the association between myeloperoxidase and blood pressure. Hypertension. 2010; 55(6): 1366-1372, doi: 10.1161/HYPERTENSIONAHA.109.147231, indexed in Pubmed: 20385972.

26. Yudkin JS, Stehouwer CD, Emeis JJ, et al. C-reactive protein in healthy subjects: associations with obesity, insulin resistance, and endothelial dysfunction: a potential role for cytokines originating from adipose tissue? Arterioscler Thromb Vasc Biol. 1999; 19(4): 972-978, doi: 10.1161/01.atv.19.4.972, indexed in Pubmed: 10195925.

27. Hingorani AD, Cross J, Kharbanda RK, et al. Acute systemic inflammation impairs endothelium-dependent dilatation in humans. Circulation. 2000; 102(9): 994-999, doi: 10.1161/01. cir.102.9.994, indexed in Pubmed: 10961963.

28. Bautista LE, Atwood JE, O'Malley PG, et al. Association between C-reactive protein and hypertension in healthy middle-aged men and women. Coron Artery Dis. 2004; 15(6): 331-336, doi: 10.1097/00019501-200409000-00006, indexed in Pubmed: 15346091.

29. Sesso HD, Buring JE, Rifai N, et al. C-reactive protein and the risk of developing hypertension. JAMA. 2003; 290(22): 2945-2951, doi: 10.1001/jama.290.22.2945, indexed in Pubmed: 14665655.

30. Fabijanić D, Banić M, Kardum D. C-reaktivni protein u procjeni kardiovaskularnog rizika. Liječ Vjesn. 2006; 128: 167-74.

31. Hak AE, Stehouwer CD, Bots ML, et al. Associations of Creactive protein with measures of obesity, insulin resistance, and subclinical atherosclerosis in healthy, middle-aged women. Arterioscler Thromb Vasc Biol. 1999; 19(8): 1986-1991, doi: 10.1161/01.atv.19.8.1986, indexed in Pubmed: 10446082.

32. Mitu F, Rezuş E, Banu C, et al. Inflammatory markers in hypertensive patients and influence of some associated metabolic risk factor. Rev Med Chir Soc Med Nat Iasi. 2014; 118(3): 631-636, indexed in Pubmed: 25341276.

33. Lakoski SG, Cushman M, Siscovick DS, et al. The relationship between blood pressure and C-reactive protein in the MultiEthnic Study of Atherosclerosis (MESA). J Am Coll Cardiol. 2005; 46(10): 1869-1874, doi: 10.1016/j.jacc.2005.07.050, indexed in Pubmed: 16286174.

34. Pankow J, Folsom A, Cushman M, et al. Familial and genetic determinants of systemic markers of inflammation: the NHLBI family heart study. Atherosclerosis. 2001; 154(3): 681-689, doi: 10.1016/s0021-9150(00)00586-4, indexed in Pubmed: 11257270.

35. Sonnenberg GE, Krakower GR, Kissebah AH. A novel pathway to the manifestations of metabolic syndrome. Obes Res. 2004; 12(2): 180-186, doi: 10.1038/oby.2004.24, indexed in Pubmed: 14981209.

36. Ridker PM. High-sensitivity C-reactive protein: potential adjunct for global risk assessment in the primary prevention of cardiovascular disease. Circulation. 2001; 103(13): 1813-1818, doi: 10.1161/01.cir.103.13.1813, indexed in Pubmed: 11282915. 